\title{
Comparative Analyses of Herbivory Rates and Leaf Phenology in Invasive and Native Shrubs in an East-Central Indiana Forest
}

Bodawatta, Kasun Harshana; Clark, Caitlin ; Hedrick, Ashley ; Hood, Andrew; Smith, Brent

Published in:

Journal of the Torrey Botanical Society

DOI:

10.3159/TORREY-D-18-00005

Publication date:

2019

Document version

Publisher's PDF, also known as Version of record

Document license:

CC BY-NC

Citation for published version (APA):

Bodawatta, K. H., Clark, C., Hedrick, A., Hood, A., \& Smith, B. (2019). Comparative Analyses of Herbivory Rates and Leaf Phenology in Invasive and Native Shrubs in an East-Central Indiana Forest. Journal of the Torrey Botanical Society, 146(1), 48 - 57. https://doi.org/10.3159/TORREY-D-18-00005 


\title{
BioOne COMPLETE
}

\section{Comparative Analyses of Herbivory Rates and Leaf Phenology in Invasive and Native Shrubs in an East-Central Indiana Forest1}

\author{
Authors: Kasun H. Bodawatta, Caitlin Clark, Ashley Hedrick, Andrew Hood,
} and Brent $\mathrm{H}$. Smith

Source: The Journal of the Torrey Botanical Society, 146(1) : 48-57

Published By: Torrey Botanical Society

URL: https://doi.org/10.3159/TORREY-D-18-00005

BioOne Complete (complete.BioOne.org) is a full-text database of 200 subscribed and open-access titles in the biological, ecological, and environmental sciences published by nonprofit societies, associations, museums, institutions, and presses.

Your use of this PDF, the BioOne Complete website, and all posted and associated content indicates your acceptance of BioOne's Terms of Use, available at www.bioone.org/terms-of-use.

Usage of BioOne Complete content is strictly limited to personal, educational, and non-commercial use. Commercial inquiries or rights and permissions requests should be directed to the individual publisher as copyright holder.

BioOne sees sustainable scholarly publishing as an inherently collaborative enterprise connecting authors, nonprofit publishers, academic institutions, research libraries, and research funders in the common goal of maximizing access to critical research. 


\title{
Comparative analyses of herbivory rates and leaf phenology in invasive and native shrubs in an east-central Indiana forest ${ }^{1}$
}

\author{
Kasun H. Bodawatta, ${ }^{2,4}$ Caitlin Clark, Ashley Hedrick, ${ }^{3}$ Andrew Hood, \\ and Brent H. Smith
}

Department of Biology, Earlham College, Richmond, IN 47374

\begin{abstract}
Exotic species that become invasive can have a strong impact on the success of native species because of traits that enhance their competitive abilities. This study investigates three potential trait differences between common invasive and native shrubs that could enhance the competitive success of invasives: resistance to herbivory, length of autumn leaf retention, and timing of spring leaf emergence. We measured herbivory per plant by leaf-chewing insects, autumn leaf color change and retention, and spring leaf-out in five native and five invasive shrub species in Wildman Woods near Richmond, Indiana, during the fall of 2014 and the spring of 2015. Although we found variation among species, native plants as a group had significantly greater percent leaf herbivory per plant compared to invasive plants, while invasive plants kept chlorophyll significantly later in autumn and had longer leaf retention. Invasive plants also leaf out slightly earlier than native species. Our findings in 2014 were very similar to previous unpublished work in the same area on several of the same species in 2002,2004, and 2007, suggesting that these patterns are consistent between years. Overall, we found evidence that lower herbivory rates, longer leaf retention in fall, and perhaps earlier leaf-out in spring could improve the competitive abilities of invasive shrub species through increased season-long photosynthesis.
\end{abstract}

Key words: enemy release, herbivory, invasive traits, leaf phenology, photosynthetic period

The majority of nonnative species introductions, both intentional and unintentional, occur due to human activities (Sakai et al. 2001). Many of these introduced exotic species do not survive or are unable to disperse in their new ecosystems. However, a small proportion of introduced species have traits that allow them to establish and spread throughout the introduced regions, and most of these species can cause both ecological and

\footnotetext{
${ }^{1}$ We are indebted to the following research teams from Earlham College's Population and Community Ecology classes for permission to use their data: Stephanie Danyi, Heather Meckel, and Shannon Murphy (2002); Lauren Hart, Rebekka Prinz, Rebecca Prosser, and Lindsey Reed (2004); and Laura Herbstreit and Stephen Martin (2007). We also thank Michael Poulsen and his lab group and two anonymous reviewers for their helpful comments on the manuscript. Finally, we thank the Earlham College biology and chemistry departments for access to laboratory facilities and to the college for providing Wildman Woods as a research site.

2 Present address: Natural History Museum of Denmark, Department of Biology, University of Copenhagen, 2100 Copenhagen East, Denmark

${ }^{3}$ Present address: Department of Ecology, Evolution, and Organismal Biology, Iowa State University, Ames, IA 50011-4009

4 Author for correspondence: kasun.bodawatta@ gmail.com

doi: 10.3159/TORREY-D-18-00005

CC Copyright 2019 by The Torrey Botanical Society

Received for publication January 15, 2018; and in revised form August 27, 2018; first published February 25, 2019.
}

economic damage (Sakai et al. 2001, Lockwood et al. 2013). These species are often able to outcompete and even extirpate native species, which is especially problematic for those that are threatened and endangered (Wilcove et al. 1998, Gurevitch and Padilla 2004, Pimentel et al. 2005, Lockwood et al. 2013). Invasive species are thus widely accepted as one of the leading causes of biodiversity loss (Lowe et al. 2000, Bax et al. 2003, Gurevitch and Padilla 2004, Didham et al. 2005, Clavero et al. 2009, McGeoch et al. 2010, Rogers et al. 2017).

Due to the potential impacts on ecosystems, investigating the traits that make an invasive species successful and able to outcompete native species is crucial to improve our understanding of the ecology of invasive species and developing strategies to manage them. There are several proposed hypotheses to explain how exotic species become invasive (Lockwood et al. 2013). Of these hypotheses, the enemy release hypothesis (Keane and Crawley 2002) has received most attention (Kleunen et al. 2010) and has provided the basic platform to other hypotheses, such as the evolution of increased competitive ability (Blossey and Nötzold 1995). The enemy release hypothesis suggests that invasive species escape from their natural enemies, such as parasites, predators, and herbivores, in the introduced area. Several studies found evidence for the enemy release hypothesis, showing that herbivory rates are lower in invasives 
in introduced areas compared to their native habitats (DeWalt et al. 2004, Cappuccino and Carpenter 2005, Vilà et al. 2005, Liu and Stiling 2006, Williams and Sahli 2016).

Another possible explanation for the success of these invasive species is that they are simply filling an available niche in the introduced habitat (Godoy et al. 2009, Penuelas et al. 2010, Lockwood et al. 2013). They might be equipped with multiple traits, such as early leaf-out (Polga et al. 2014), early leaf development (McEwan et al. 2009), longer leaf retention (Resasco et al. 2007, McEwan et al. 2009, Fridley 2012, Smith 2013), faster leaf economic returns (Penuelas et al. 2010), and/or low herbivory rates (Vilà et al. 2005, Averill et al. 2016, Williams and Sahli 2016), that enable them to exploit different niches in the new habitats. Ultimately, these traits can provide invasive species with a competitive advantage over native species.

Although there are a number of studies that investigate either herbivory (Zou et al. 2008, Buswell et al. 2011, Averill et al. 2016) or leafing phenology (Resasco et al. 2007, McEwan et al. 2009, Fridley 2012, Polga et al. 2014) between invasive and native plants, to date no studies have considered both simultaneously and over multiple years at the same location. In order to fully understand how these invasive species are able to establish and spread successfully in their introduced habitats, it is important to investigate multiple traits that might provide a competitive advantage for invasives over natives. It is also important to see how consistent patterns of herbivory and leaf phenologies are over time both within and between native and invasive species. In this study, we investigate three ecological factors: (a) leaf herbivory by insects (almost exclusively in this case); (b) leaf retention in autumn, including chlorophyll retention measured by color change; and (c) the timing of leaf-out and leaf expansion in spring. In 2014, we chose five common native and five common invasive shrub species in an eastcentral Indiana forest in order to investigate whether invasive species experience a higher photosynthetic capacity due to reduced herbivory and an extended photosynthetic period. To evaluate if differences in herbivory and leaf phenology are consistent over time, we compared our findings to unpublished data collected in 2002, 2004, and 2007 by other research teams working with similar species groups in the same study site using the same or very similar methods.

Methods. Our study was conducted in Wildman Woods $\left(39^{\circ} 47^{\prime} 56.9^{\prime \prime} \mathrm{N}, 84^{\circ} 57^{\prime} 39.8^{\prime \prime} \mathrm{W}\right)$ in eastcentral Indiana throughout the autumn of 2014 and spring of 2015. Wildman Woods is a 16-ha temperate deciduous forest owned by Earlham College and managed as a nature preserve and research area. The woods is a mixture of oldgrowth and younger successional forest, the latter developing from pasture abandoned in 1940. Both stand types have a closed canopy, but the younger stands have a denser shrub layer. Almost all of our data were collected from these younger stands.

To study leafing phenology and degree of leaf herbivory in 2014, we selected five native plant species-Lindera benzoin (Spicebush, Lauraceae), Ribes cynosbati (Wild Gooseberry, Grossulariaceae), Rubus spp. (Blackberry, Rosaceae), Viburnum acerifolium (Maple-leaved Viburnum, Adoxaceae), and Viburnum prunifolium (Cherryleaved Viburnum, Adoxaceae) - and five invasive species-Berberis thunbergii (Japanese Barberry, Berberidaceae), Elaeagnus umbellata (Autumn Olive, Elaeagnaceae), Euonymus alatus (Winged Euonymus/Burning Bush, Celastraceae), Lonicera maackii (Amur Honeysuckle, Caprifoliaceae), and Rosa multiflora (Multiflora Rose, Rosaceae). In addition, we report data from the invasive Ligustrum vulgare (Privet, Oleaceae) from 2002 and 2007. These species are the most common native and invasive shrubs in this forest and in forests regionally (Deam 1932, Swink and Wilhelm 1994, Nagle 2012, B.H.S., personal observation).

First, we selected 20 individual plants from each species that were distributed throughout the study area. All the plants were growing along the trails, and we used a random number table to select individuals in different areas to avoid sampling bias and to try to study each species in the variety of microhabitats in which it occurs. To measure leaf herbivory, we selected a branch and haphazardly collected 20 leaves from it, totaling 400 leaves from each species $(20$ leaves $\times 20$ individuals) on October 20, 2014. We recorded the presence or absence of herbivory of each leaf to examine the frequency of damaged leaves on each individual shrub. Of the collected damaged leaves, we haphazardly selected one leaf per plant and determined the extent of herbivory by 


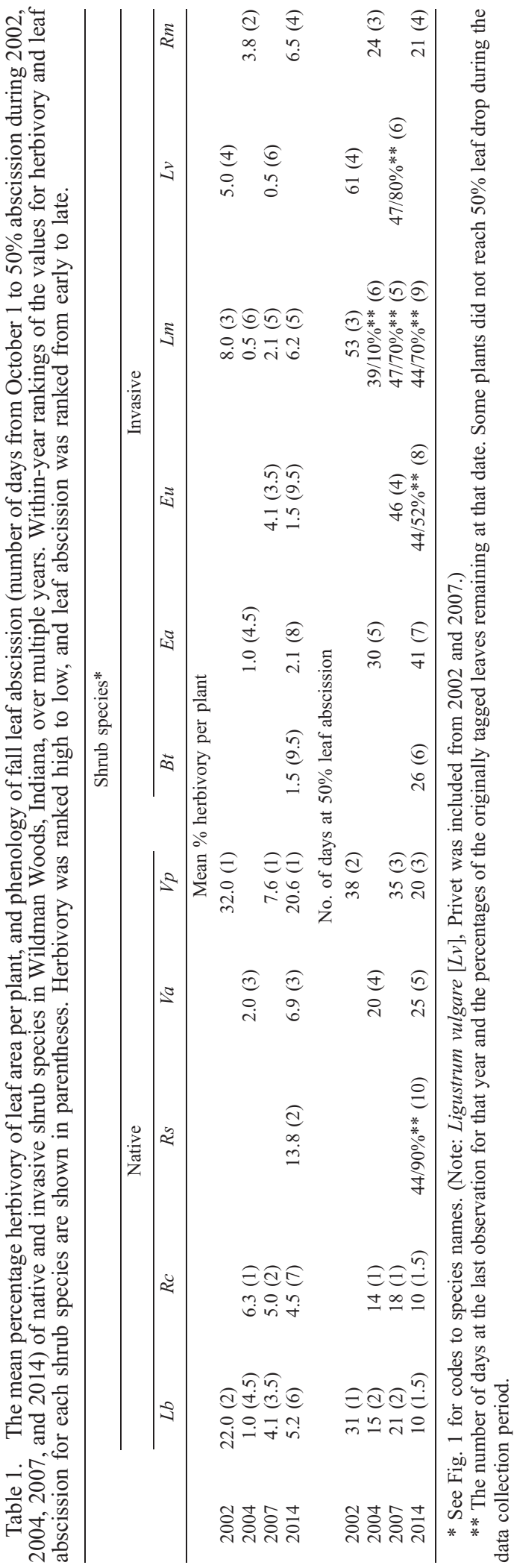

measuring the proportion of leaf damage using a paper cutout method. First, we outlined the estimated preherbivory leaf borders of the selected leaf on an index card, cut out that leaf outline, and weighed it. We then outlined the consumed area, cut it out, and reweighed the piece of the card. The difference in mass was used to calculate the percentage of the leaf eaten. We calculated herbivory damage per plant by multiplying the frequency of leaves with herbivory with the proportion eaten from the randomly chosen leaf with herbivory, assuming that the chosen leaf was representative of the population of leaves on the plant. Note that our methods were designed primarily to measure leaf herbivory by phytophagous insects and not browsers, such as deer, that typically take whole leaves or parts of branches. Although common elsewhere (e.g., Martinrod and Gorchov 2017), we encountered deer-related herbivory only rarely in our 2014 study, and the same was true in previous years (see below and "Discussion").

To measure autumn chlorophyll and leaf retention on a shrub, we selected a different set of 20 plants from each of our study species on September 20, 2014, prior to autumnal color change. On each plant, we selected one branch and censused the 10 most distal leaves on that branch weekly from September 25 to November 13. At each census, we recorded the number of leaves remaining and their color (i.e., green, yellow, red). The individuals that did not drop their leaves by November 13 were checked again on December 4 and 18 to record the leaf abscission progress.

For leaf-out in spring, we haphazardly selected a branch for each of 20 individuals from each plant species and visited all plants weekly from March 11 to May 5, 2015, noting the presence of buds, bud color, and the first appearance of leaves. Leafout in a branch occurred when all the leaf blades on an entire branch had uncurled completely (note that individual leaves continue to expand in size after leaf-out). We graphed our leaf-out data for each species and estimated the number of days (from March 11) it took for 50\% and 100\% of the plants to reach the leaf-out stage.

The methods we used to assess leaf herbivory and fall leaf retention were very similar to three earlier student projects conducted in Wildman Woods in 2002, 2004, and 2007, though sample sizes varied. However, leaf color change was not 


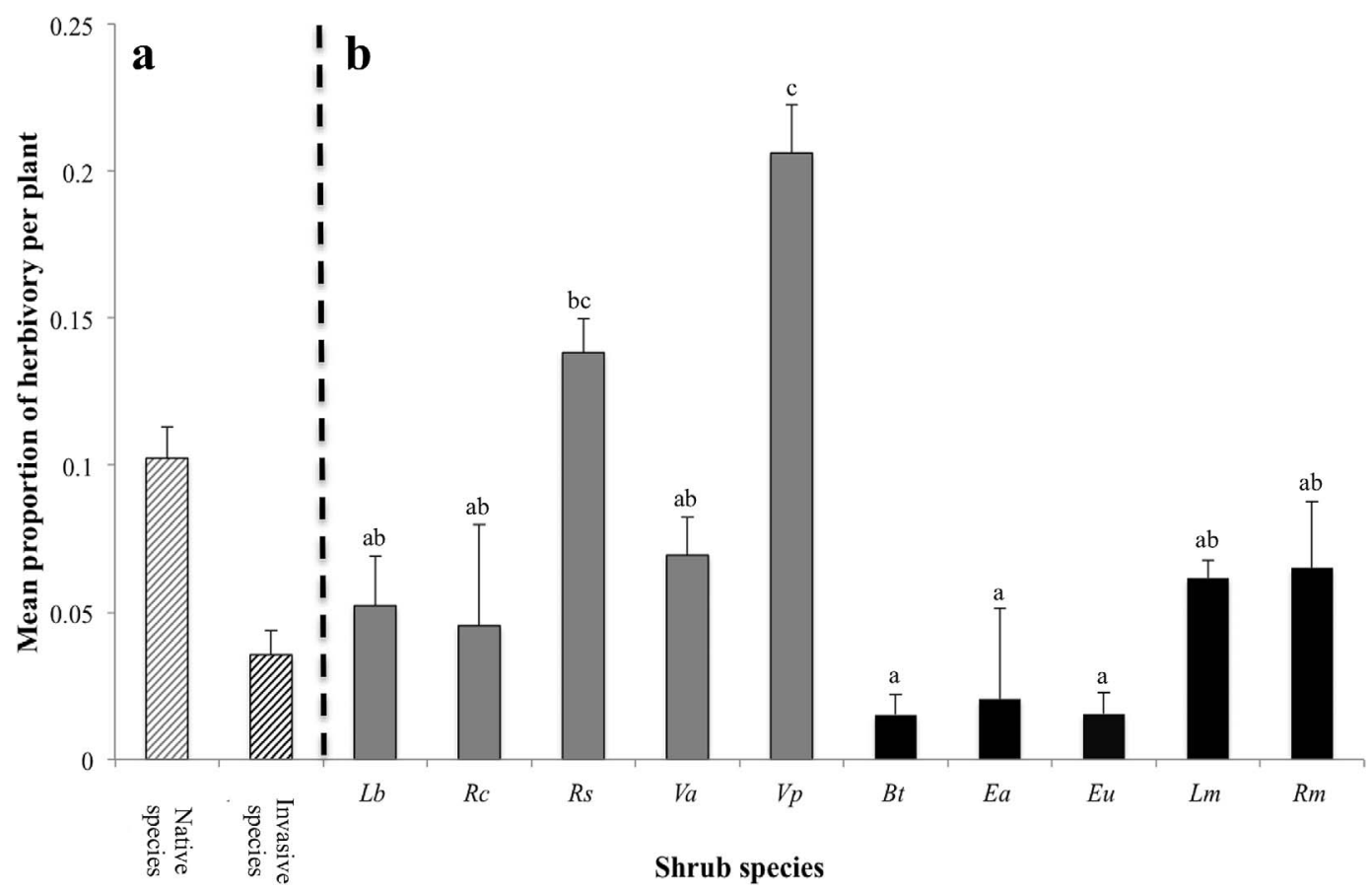

FIG. 1. Mean proportion of herbivory per plant $( \pm S E)$ in 2014 for (a) all native and invasive shrub species (one-way analysis of variance: $F_{1,198}=51.38, P=0.038$ ) and (b) individual species: native shrubs (Lindera benzoin $[L b]$, Ribes cyanosbati [Rc], Rubus spp. [Rs], Viburnum acerifolium [Va], and Viburnum prunifolium $[\mathrm{Vp}]$ ) and invasive shrubs (Berberis thunbergii [Bt], Euonymus alatus [Ea], Elaeagnus umbellata [Eu], Lonicera maackii $[\mathrm{Lm}]$, and Rosa multiflora $[\mathrm{Rm}]$ ) (Kruskal-Wallis test statistic $=85.83, P<0.001)$. Letters represents results of the Dunn's post hoc test $(P<0.05)$. Native species are represented by gray bars and invasive species by black bars.

assessed in any of these studies; only leaf abscission was censused. In addition, spring leafout was not investigated in these prior studies.

We used Past 3.14 statistical software to perform one-way analyses of variance (ANOVAs) to test for differences in leafing phenology and herbivory between native and invasive species. Herbivory and leaf-drop data among species, even after data transformation, showed significant deviations from normality (Kolmogorov-Smirnov test) and homogeneity of variance (Levene test). Therefore, we used Kruskal-Wallis (K-W) nonparametric tests and Dunn's post hoc comparisons. Although we test for differences using K-W, we report means and standard errors (rather than mean ranks) in figures so that the actual percentage herbivory and the phenologies of color change, leaf drop, and leaf-out can be visualized.

Results. Our 2014 results show that, on average, native plant species have significantly higher rates of herbivory as compared to invasive species (Fig. 1a). Among the five native species, two (Rubus spp. and V. prunifolium) were highly consumed by insect herbivores, and all of the invasive species had lower herbivory rates than these two native species (Fig. 1b). In addition, three of the invasive species (E. umbellata, $B$. thunbergii, and $E$. alatus) had lower leaf herbivory than all five native plant species.

Overall, native species changed leaf color significantly earlier than invasives by approximately 16 days (22 days excluding Rubus spp.) (Fig. 2a). Rubus spp. are an exception, changing leaf color and dropping leaves much later than other native species (Fig. 2b and 3). Natives lose $50 \%$ of their leaves approximately 11 days $(21$ days excluding Rubus spp.) earlier than invasives (one-way ANOVA: $F_{1,161}=21.95, P<0.001$ ), and by November 13 , natives lost approximately $22 \%$ (40\% excluding Rubus spp.) more leaves than invasives (Fig. 3; one-way ANOVA: $F_{1,198}=$ 16.92, $P<0.001)$. Again, Rubus spp. retained their leaves longer than other native species, while 


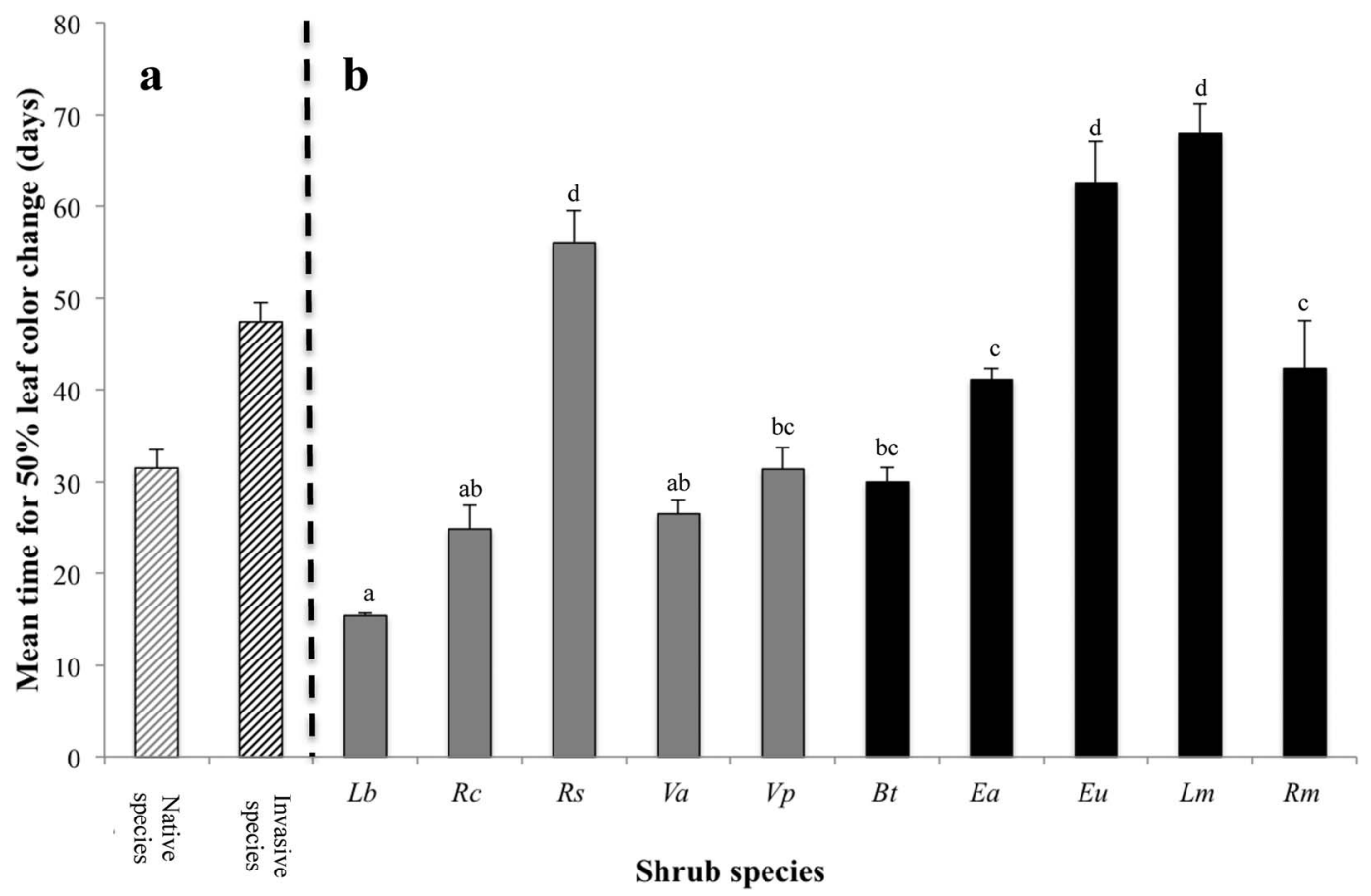

FIG. 2. Mean number of days ( \pm SE) (from September 25, 2014) for 50\% of leaves to change color in (a) all the native and invasive shrub species (one-way ANOVA: $F_{1,165}=31.29, P<0.001$ ) and (b) individual species: native shrubs and invasive shrubs (Kruskal-Wallis test statistic $=125.4, P<0.001$ (species symbols are same as in Fig. 1). Letters represent results of the Dunn's post hoc test $(P<0.05)$. Native species are represented by gray bars and invasive species by black bars.

all of the invasive species retained their leaves longer than all native species with the exception of Rubus spp. L. maackii and E. umbellata, two of the most abundant invasives in east-central Indiana (Nagle 2012, B.H.S., personal observation), retained higher proportions of their leaves for a longer period of time (Fig. 3).

The invasives $B$. thunbergii, R. multiflora, and E. umbellata leafed out earlier in spring than other shrub species (Fig. 4). Invasive plants collectively reached $100 \%$ branch leaf-out an average of 8.6 days earlier (around April 16) than native plants (around April 23) (one-way ANOVA: $F_{1,198}=$ 6.748, $P=0.032$ ).

The patterns that prior research teams in 2002, 2004, and 2007 found on leaf herbivory and autumn leaf retention in Wildman Woods compare to our 2014 investigation in Fig. 5 and Table 1. Although percent herbivory per plant and the dates for $50 \%$ leaf abscission varied among years within species, the relative rankings of the two characteristics were similar across the 4 yrs. Furthermore, during all 4 yrs, native species as a group had higher percent herbivory and earlier leaf abscission in the autumn than invasives (Fig. 5; Table 1).

Discussion. Our results show that, as a group, invasive shrubs have lower herbivory rates (Fig. 1) and longer photosynthetic periods (Fig. 2-4) than native species and that this pattern is consistent across years (Fig. 5; Table 1). Lower herbivory and a longer growing season could contribute to the competitive success of invasives over native species, as many have asserted (e.g., Resasco et al. 2007, Fridley 2012, Polga et al. 2014). Decreased herbivory likely allows invasives to maintain higher growth rates than natives due to increased leaf surface area and reduced woundassociated physiological costs (Zou et al. 2008). Reduced insect herbivory in invasives is consistent with the enemy release hypothesis (Keane and Crawley 2002), which asserts that invasives have escaped from their coevolved herbivores in their native region and that herbivores in the introduced area have not adapted to utilize them as food sources. However, without a proper comparison of herbivory rates in the native areas of these invasive 


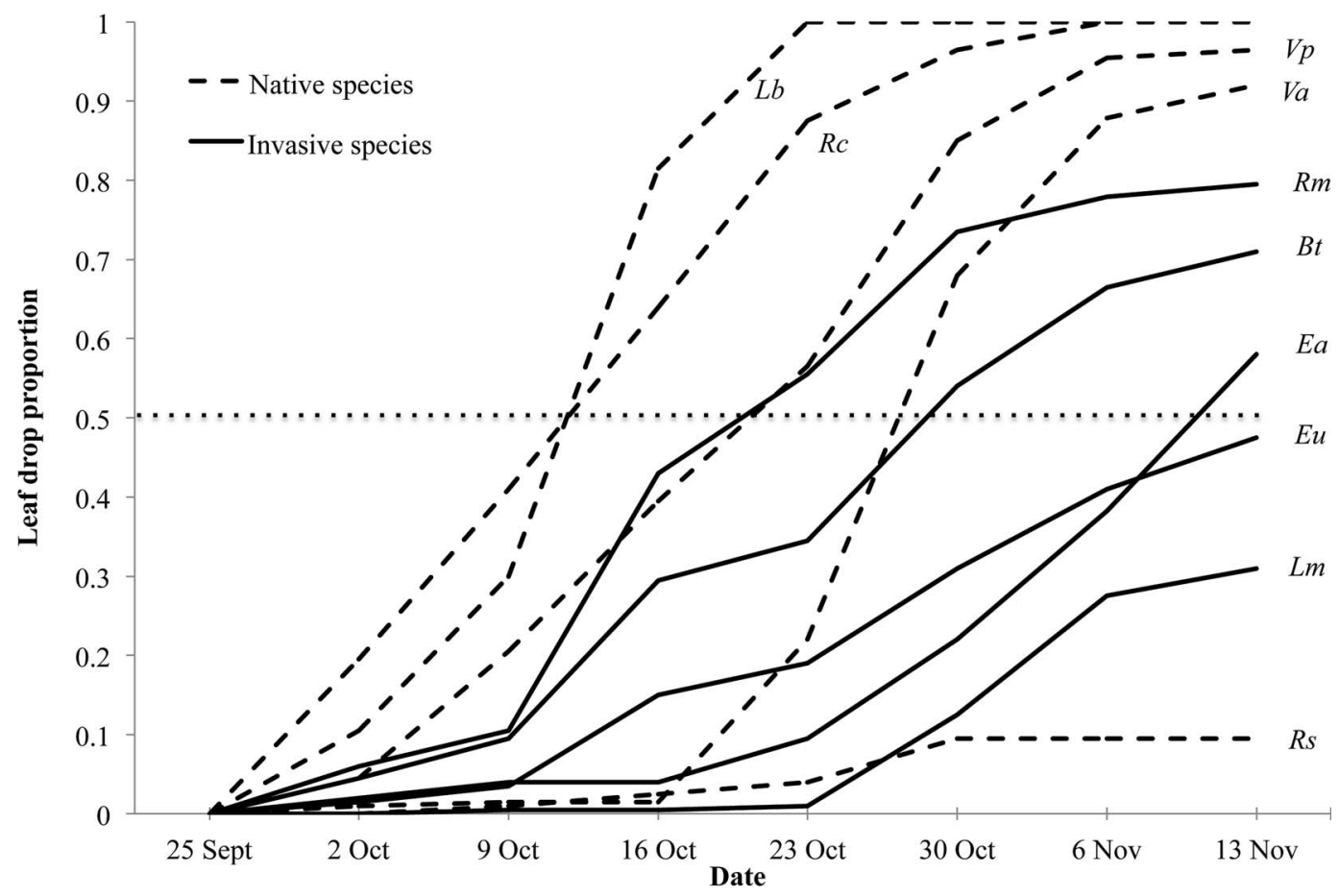

FIG. 3. Timing of leaf drop in five native shrub species and five invasive shrub species (species symbols are same as in Fig. 1) between September 25 and November 13, 2014. The dotted line represents 50\% leaf drop.

species, it is difficult to confirm that invasives experience lower herbivory in introduced habitats due to the escape from their native herbivores. Our finding of reduced insect herbivory in invasive species is consistent with many other studies that investigated the impact of herbivores on invasive species in their introduced habitats (DeWalt et al. 2004, Cappuccino and Carpenter 2005, Vilà et al. 2005, Liu and Stiling 2006, Williams and Sahli 2016).

Our "snapshot" leaf harvesting methods of studying insect leaf herbivory are not useful in quantifying deer browsing of shrubs. However, the hundreds of leaves and branches that we studied for leaf phenology over many weeks in both the spring and the fall remained virtually untouched by deer in our study sites regardless of native or invasive status and regardless of year. This contrasts with studies that have found deer browse to have a larger impact than insect herbivory (e.g., Averill et al. 2016, Martinrod and Gorchov 2017). We simply might not have had enough leaf observation stations to adequately measure the impact of deer browsing, or, more likely, the low browsing we observed reflects the heavy hunting pressure on deer herds in Wildman Woods and surrounding properties.

The extended growing season of invasives, through early spring leaf-out and longer leaf retention in the autumn, likely increases the overall competitiveness of invasives over native species (Smith 2013). Early leaf-out in spring is essential for many understory shrubs since they will soon be shaded as canopy trees leaf out. The average 8.6day-earlier leaf-out in invasive shrubs likely gives them a competitive advantage over native shrubs by both initiating photosynthesis earlier and shading them during this window of high light intensity in early spring. Earlier leaf-out of invasive shrubs can also have a detrimental impact on forest understory herbs, particularly shadeintolerant spring ephemerals, by reducing the highlight spring phenoseason prior to tree canopy leafout (Hutchinson and Vankat 1997, Gordon 1998, Collier et al. 2002, Miller and Gorchov 2004, Christopher et al. 2014). Although there are multiple advantages to early leaf-out, there are also possible costs associated with this trait, such as loss of leaves due to late frost and reduced conductivity capacity in xylem tissues (Lechowicz 


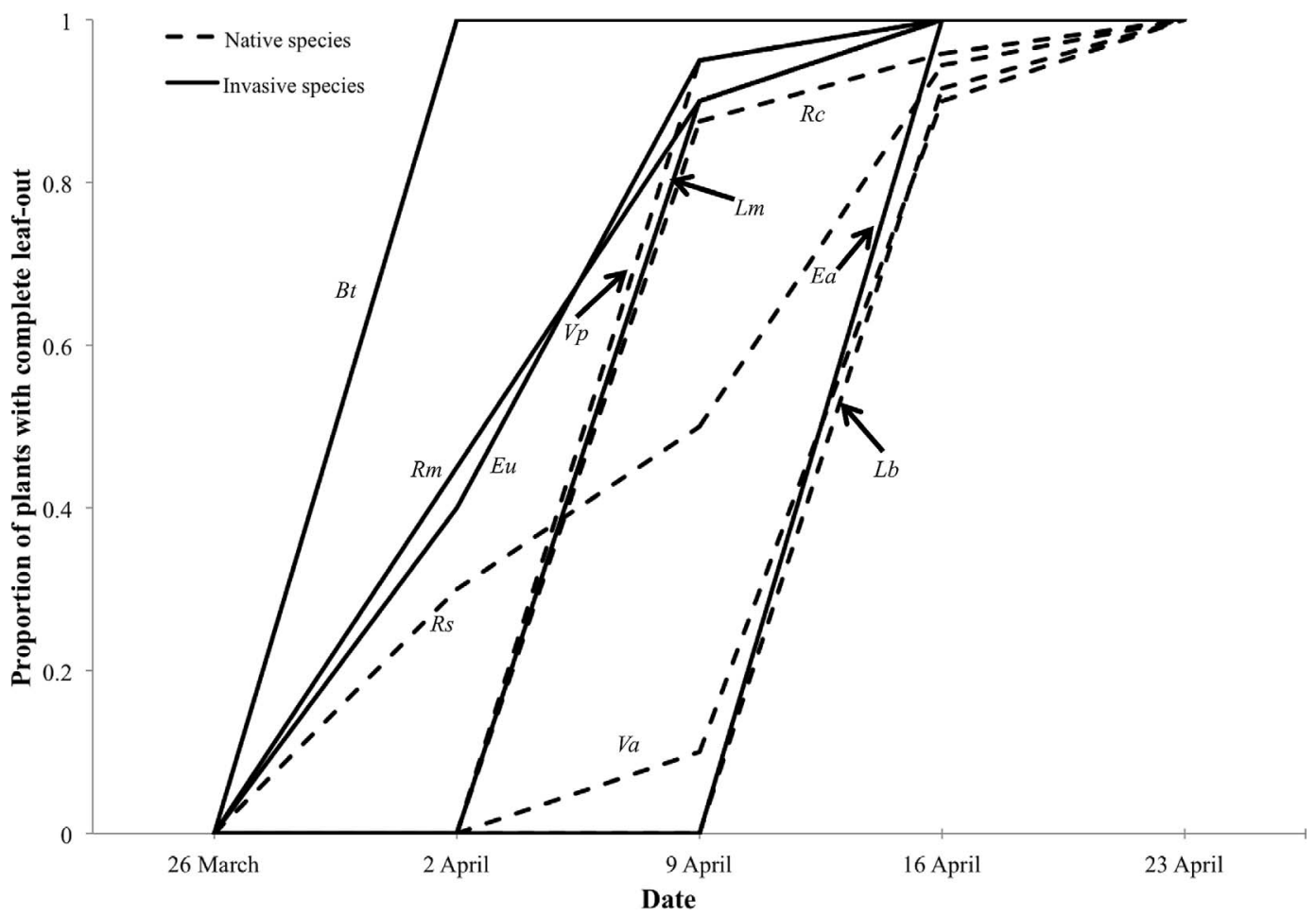

FIG. 4. Timing of branch-level leaf-out in five native (dashed lines) and five invasive (solid lines) shrub species (species symbols are same as in Fig. 1) between March 19 and April 22, 2015 in Wildman Woods.

1984). These invasive plants might have adapted to dealing with these costs in their native ranges.

The later chlorophyll breakdown (color change) and leaf drop of invasive plants in the autumn also provide significantly longer growth periods (approximately 22 days excluding Rubus spp.), which is consistent with other studies conducted in the eastern United States (McEwan et al. 2009, Fridley 2012). All of these common invasive plants in Indiana are native to East Asia, including China, Japan, and the Korean Peninsula (Silander and Klepeis 1999, National Park Service 2010). Both the native ranges of these shrubs in eastern Asia and their invasive ranges in the United States occur at similar latitudes and have similar climatic conditions (Hijmans et al. 2005, Chen et al. 2017). Therefore, variation in autumn day length likely does not explain the longer leaf retention in these Asian shrub species. However, differences in historic climatic conditions may play a role. Lechowicz (1984) suggests that the relatively shorter leaf phenology of native shrub species in eastern North America might be a relict of the more variable climatic conditions during the Pleistocene compared to East Asia. Hence, the longer leafing period of East Asian invasive shrubs may be a preadaptation to success in present-day eastern North American forests (Mack 2003, Fridley 2012).

Leaf phenology may, however, also be controlled by other strategies of invasive plants, such as freeze tolerance levels in L. maackii (McEwan et al. 2009) and nitrogen fixing ability in $E$. umbellata (Clark et al. 2008). These traits can increase the invasiveness of these introduced species and provide extra competitive advantage over native species. The ability to fix nitrogen can reduce the necessity of early chlorophyll absorbance in fall and lead to an extended photosynthetic period. Similarly, freeze tolerance can allow early leaf-out in spring, while there is still a risk of frost and delay leaf abscission until late autumn, leading to an increase in photosynthetic capacity over native species.

Although invasives tend to retain their leaves longer in the autumn than natives, we found variation in this character between species. Among invasives, chlorophyll and leaf retention were significantly longer in L. maackii and E. umbellata than B. thunbergii, E. alatus, and R. multiflora 


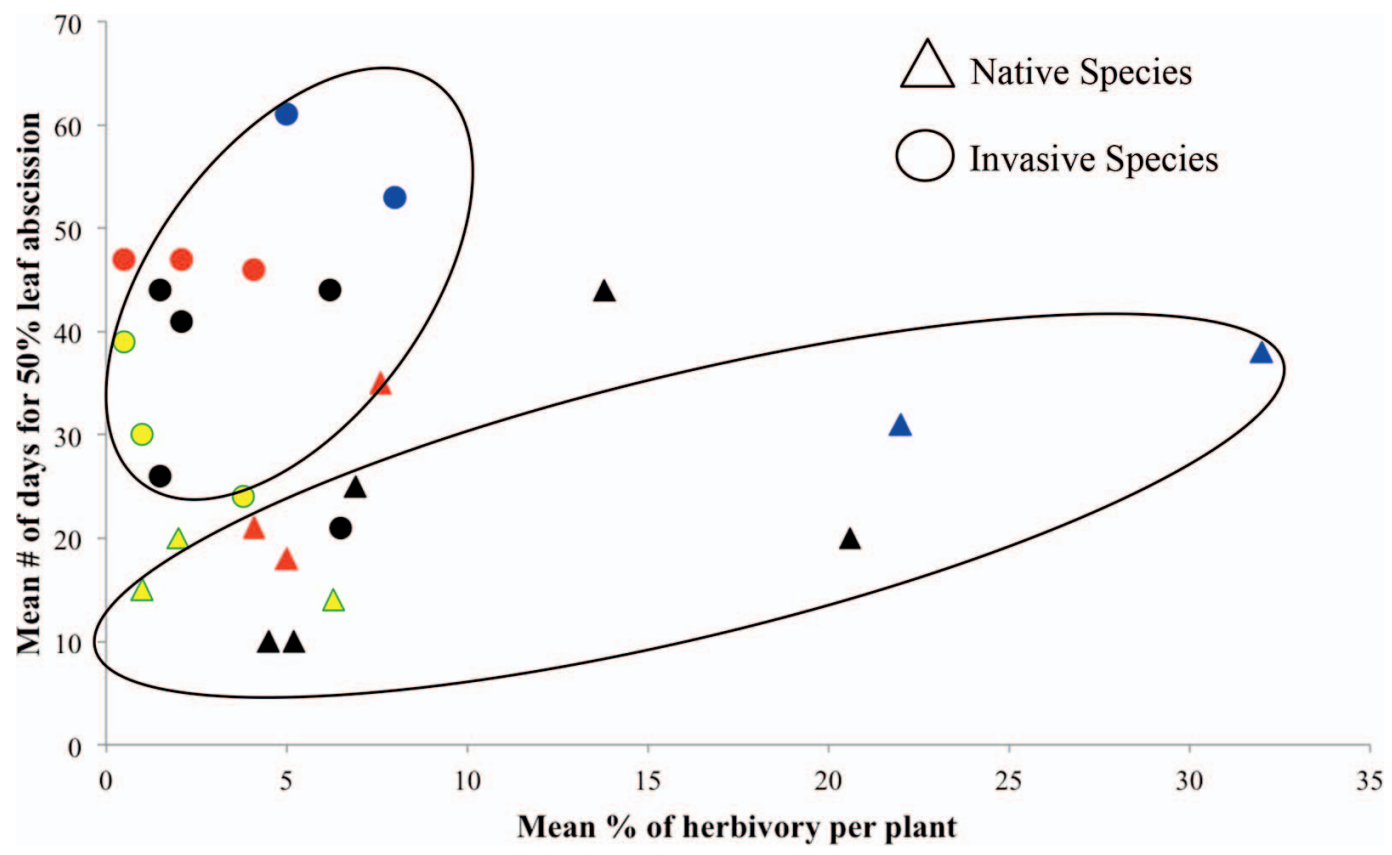

FIG. 5. The relationship between mean percent herbivory and mean number of days for $50 \%$ leaf abscission (from October 1) in 2002 (blue), 2004 (yellow), 2007 (red), and 2014 (black) in native (triangles) and invasive (circles) plants in Wildman Woods. Ellipses are drawn capturing most of invasive or native data points. The triangle in the invasive species zone represents the data for Rubus spp., which acted like an invasive species with respect to leaf abscission.

(Fig. 2). We do not know the reasons for these differences. Perhaps the nursery stock from these escaped garden and farm species came from different latitudes. It may not be coincidental, however, that L. maackii and E. umbellata also form the densest thickets and are the most destructive of the invasives in this region (Nagle 2012, B.H.S., personal observation).

Among the natives, Rubus spp. stand out in having much longer chlorophyll and leaf retention in the autumn than other natives, and in fact leaf color change occurs in later than all but L. maackii and E. umbellata (Fig. 2). Rubus spp. are forest edge invaders in east-central Indiana, and it has invaded disturbed parts of Wildman Woods that were open canopy areas as recently as the 1960s, according to aerial photographs of the site (Wayne County, IN, Surveyor Department). It is possible that the longer leaf retention and delayed degradation of chlorophyll is an adaptation that, like present-day invasives, enhances its competitive ability over other native species. The blackberry section within the genus Rubus is notoriously complex taxonomically, with high degrees of hybridization, polyploidy, and apomixis (e.g.,
Gleason and Cronquist 1991). If the Pleistocene hypothesis outlined by Lechowicz (1984) is correct, the genetic milieu of this complex, particularly extensive recombination (Prentis et al. 2008) may have allowed natural selection to shift trait frequencies more rapidly in this taxon in post-Pleistocene North America in situ.

Low herbivory rates that we have found in invasive species appear to some degree to support the enemy release hypothesis. However, the lack of data on herbivory rates on these invasive species in their native ranges makes this conclusion tentative. We also found evidence that longer leaf life, perhaps a preadaptation to different Pleistocene climatic conditions in their native Asian origins, may contribute to the competitive success of invasive shrubs in eastern North America today. To better understand why these species are successful invaders in these forest habitats, further research will need to be conducted comparing the native home ranges of these species and the selective pressures that they are under in their native habitats. Comparative research on herbivory rates (DeWalt et al. 2004), leafing phenology, growth rates (Schierenbeck et al. 1994), genetic 
diversity (Hollingsworth and Bailey 2000, Kelager et al. 2013), and fundamental and realized niches of these species (Broennimann et al. 2007, Tingley et al. 2014) can increase our knowledge on the invasive ecology of these species.

Conclusion. Our study provides more evidence that invasive shrub species as a group retain more leaf area, via reduced insect herbivory and have a longer photosynthetic period, through earlier leafout in the spring and longer leaf retention in the fall, compared to their native counterparts. These three traits, taken together, likely enhance seasonlong photosynthetic capabilities. The increased net growth likely gives invasive species a distinct fitness advantage because they have more energy to allocate toward growth and reproduction over native species, providing a competitive advantage. Overall, this study (and others before us) provides evidence that the success of invasive shrub species in eastern United States is plausibly due to their photosynthetic gain over native species.

\section{Literature Cited}

Averill, K. M., D. A. Mortensen, E. A. H. Smithwick, AND E. Post. 2016. Deer feeding selectivity for invasive plants. Biol. Invasions 18: 1247-1263.

Bax, N., A. Williamson, M. Aguero, E. Gonzalez, and W. GeEves. 2003. Marine invasive alien species: A threat to global biodiversity. Mar. Policy 27: 313-323.

Blossey, B. AND R. NöTzold. 1995. Evolution of increased competitive ability in invasive nonindigenous plants: A hypothesis. J. Ecol. 83: 887-889.

Broennimann, O., U. A. Treier, H. Müller-Schärer, W. Thuiller, A. T. Peterson, A. Guisen. 2007. Evidence of climatic niche change during biological invasion. Ecol. Lett. 10: 701-709.

Buswell, J. M., A. T. Moles, and S. Hartley. 2011. Is rapid evolution common in introduced plant species? J. Ecol. 99: 214-224.

Cappuccino, N. and D. Carpenter. 2005. Invasive exotic plants suffer less herbivory than non-invasive exotic plants. Biol. Lett. 1: 435-438.

Chen, Y., L. Vasseur, and L. You. 2017. Potential distribution of the invasive loblolly pine mealybug, Orecella acuta (Hemiptera: Pseudococcidae) in Asia under future climatic scenarios. Clim. Change 141: 719-732.

Christopher, C. C., S. F. Matter, and G. N. Cameron. 2014. Individual and interactive effects of Amur honeysuckle (Lonicera maackii) and white-tailed deer (Odocoileus virginianus) on herbs in a deciduous forest in the eastern United States. Biol. Invasions 16: 2247-2261.

Clark, J. R., G. E. Hemery, and P. S. Sevill. 2008. Early growth and form of common walnut (Juglans regia $\mathrm{L}$.) in mixture with tree and shrub nurse species in southern England. Forestry 81: 631-644.
Clavero, M., L. Brontons, P. Pons, and D. Sol. 2009. Prominent role of invasive species in avian biodiversity loss. Biol. Conserv. 14: 2043-2049.

Collier, M. H., J. L. Vanket, and M. R. Hughes. 2002. Diminished plant richness and abundance below Lonicera maackii, an invasive shrub. Am. Midl. Nat. 147: 60-71.

DeAm, C. C. 1932. Shrubs of Indiana. Indiana Department of Conservation, Indianapolis, IN.

DeWalt, S. J., J. S. Denslow, and K. Ickes. 2004. Natural enemy release facilitate habitat expansion of the invasive tropical shrub Clidemia hirta. Ecology 85: 471-483.

Didham, R. K., J. M. Tylianakis, M. A. Hutchison, R. M. Ewers, AND N. J. Gemmell. 2005. Are invasive species the drivers of ecological change? Trends Ecol. Evol. 20: $470-474$.

FridLEY, J. D. 2012. Extended leaf phenology and the autumn niche in deciduous forest invasions. Nature 485: 359-362.

Gleason, H. A. And A. Cronquist. 1991. Manual of Vascular Plants of Northeastern United States and Adjacent Canada, 2nd ed. New York Botanical Garden, Bronx, NY.

Godoy, O., P. Castro-Díez, F. Valladares, and M. CostaTENorio, M. 2009. Different flowering phenology of alien invasive species in Spain: Evidence for the use of an empty temporal niche? Plant Biol. 11: 803-811.

Gordon, D. R. 1998. Effects of invasives, non-indigenous plants species on ecosystem processes: Lessons from Florida. Ecol. Appl. 8: 975-989.

Gurevitch, J. G. and D. K. Padilla. 2004. Are invasive species a major cause of extinctions? Trends Ecol. Evol. 19: 470-474.

Hijmans, R. J., S. E. Cameron, J. L. Parra, P. G. Jones, AND A. JARVIS. 2005. Very high resolution interpolated climate surfaces for global land area. Int. J. Climatol. 25: 1965-1978.

Hollingsworth, M. L. And J. P. Bailey. 2000. Evidence for massive clonal growth in the invasive weed Fallopia japonica (Japanese Knotweed). Bot. J. Linn. Soc. 133: $463-472$.

HutChinson, T. F. AND J. L. VANKAT. 1997. Invasibility and effect of Amur honeysuckle in southwestern Ohio forests. Conserv. Biol. 11: 1117-1124.

Keane, R. M. and M. J. Crawley. 2002. Exotic plant invasions and the enemy release hypothesis. Trends Ecol. Evol. 17: 164-170.

Kelager, A., J. S. Pedersen, and H. H. Brunn. 2013. Multiple introductions and no loss of genetic diversity: Invasion history of Japanese Rose, Rosa rugosa, in Europe. Biol. Invasions 15: 1125-1141.

Kleunen, M. V., Dawson, W., Schlaepfer, D., Jeschke, J. M., AND Fischer, M. 2010. Are invaders different? A conceptual framework of comparative approaches for assessing determinants of invasiveness. Ecol. Lett. 13: 947-958.

Lechowicz, M. J. 1984. Why do temperate deciduous trees leaf out at different times? Adaptation and ecology of forest communities. Am. Nat. 124: 821-842.

Liu, H. and Stiling, P. 2006. Testing the enemy release hypothesis: a review and meta-analysis. Biol. Invasions 8: 1535-1545. 
Lockwood, J. L., M. F. Hoopes, and M. P. Marchetti. 2013. Establishment success: The influence biotic interactions, pp. 130-154. In J. L. Lockwood, M. F. Hoopes, and M. P. Marchetti [eds.], Invasion Ecology, 2nd ed. Blackwell, Hoboken, NJ.

Lowe, S., M. Brown, S. Boudjelas, and M. De Poorter. 2000. 100 of the World's Worst Invasive Alien Species: A Selection from the Global Invasive Species Database. Invasive Species Specialist Group, Auckland, New Zealand:.

Martinod, K. L. And D. L. Gorchov. 2017. White-tailed deer browse on an invasive shrub with extended leaf phenology meets assumptions of an apparent competition hypothesis. AoB Plants 9: plx006. doi.org/10. 1093/aobpla/plx006.

MACK, R. N. 2003. Phylogenetic constraint, absent life forms, and preadapted alien plants: A prescription for biological invasions. Int. J. Plant Sci. 164: 185-196.

McEwan, R. W., M. K. Birchield, A. Schoergendorger, AND M. A. Arthur. 2009. Leaf phenology and freeze tolerance of the invasive shrub Amur honeysuckle and potential native competitors. J. Torrey Bot. Soc. 136: 212-220.

McGeoch, M. A., S. H. Butchart, D. Spear, E. Marais, E. J. Kleynhans, A. Symes, J. Chanson, and M. Hoffmann. 2010. Global indicators of biological invasion: Species numbers, biodiversity impact and policy responses. Divers. Distrib. 16: 95-108.

Miller, K. E. AND Gorchov, D. L. The invasive shrub Lonicera maackii reduces growth and fecundity of perennial forest herbs. Oecologia 139: 359-375.

Nagle, A. 2012. Official IISC invasive plant list. Retrieved March 13, 2018 from Indiana Invasive Species Council. < https://www.entm.purdue.edu/iisc/ invasiveplants.php $>$.

National Park Service. 2010. Weeds gone wild. Retrieved May 24, 2017 from National Park Service. <https:// www.nps.gov/plants/alien/>.

Penuelas, J., J. Saedans, J. Llusià, S. M. Owen, J. Carnicer, T. W. Giambelluca, E. L. Rezendes, M. WAite, AND Ü Nirnemets. 2010. Faster returns on "leaf economics" and different biochemical niche in invasive compared with native plant species. Glob. Change Biol. 16: 2171-2185.

Pimentel, D., R. Zuniga, And D. Morrison. 2005. Update on the environmental and economic costs associated with alien-invasive species in the United States. Ecol. Econ. 52: 273-288

Polga, C., A. Gallinat, and R. B. Primack. 2014. Drivers of leaf-out phenology and their implications for species invasions: Insights from Thoreau's concord. New Phytol. 202: 106-115.

Prentis, P. J., J. R. U. Wilson, E. E. Dormontt, D. M. Richardson, AND A. J. Lowe. 2008. Adaptive evolution in invasive species. Trends Plant. Sci. 13: 288-294.

Resasco, J., A. N. Hale, M. C. Henry, and S. L. Gorchov. 2007. Detecting an invasive shrub species in a deciduous forest understory using late-fall Landsat sensory imagery. Int. J. Remote Sens. 28: 3739-3745.

Rogers, H. S., E. R. Buhle, J. HilleRisLambers, E. C. Fricke, R. H. Miller, and J. J. Tewksbury. 2017. Effects of an invasive predator cascade to plants via mutualism disruption. Nat. Commun. 8: 14557. doi:10. 1038/ncomms 14557.

Sakai, A. K., F. W. Allendorf, J. S. Holt, D. M. Lodge, J. Molofsky, S. Baughman, R. J. Cabin, J. E. Cohen, N. C. Ellstrand, D. E. McCauley, P. O’Neil, I. M. Parker, J. N. Thompson, and S. G. Weller. 2001. The population biology of invasive species. Annu. Rev. Ecol. Syst. 32: 305-332.

Schierenbeck, K. A., R. N. Mack, and R. R. Sharitz. 1994. Effect of herbivory on growth and biomass allocation in native and invasive species of Lonicera. Ecology 75: 1661-1672.

Silander, J. A. AND D. M. Klepeis. 1999. The invasion ecology of Japanese Barberry (Barberis thunbergii) in the New England landscape. Biol. Invasions 1: 189201.

Smith, L. M. 2013. Extended leaf phenology in deciduous forest invaders: Mechanisms of impact on native communities. J. Veg. Sc. 24: 979-987.

Swink, F. AND G. Wilhelm. 1994. Plants of the Chicago Region. Indiana Academy of Science, Indianapolis, IN.

Tingley, R., M. Vallinoto, F. Sequeira, and R. Kearney. 2014. Realized niche shift during a global biological invasion. Proc. Natl Acad. Sci. 111: 10233-10238.

VILÀ, M., J. L. Maron, AND L. Marco. 2005. Evidence for the enemy release hypothesis in Hypericum perforatum. Oecologia 142: 474-179.

Wilcove, D. S., D. Rothstein, J. Dubow, A. Phillips, And E. Losos. 1998. Quantifying threats to imperiled species in the United States. Bioscience 48: 607-615.

Williams, V. J. and H. F. Sahli. 2016. A comparison of herbivore damage on three invasive plants and their native congeners: Implications for the enemy release hypothesis. Castanea 81: 128-137.

Zou, J., W. E. Rogers, And E. Siemann. 2008. Increased competitive ability and herbivory tolerance in the invasive plant Sapium sebiferum. Biol. Invasions 10: 291-302. 